\title{
Effect of heat treatment on phase structure and thermal conductivity of a copper-infiltrated steel
}

\author{
S. Klein · S. Weber $\cdot$ W. Theisen
}

Received: 26 November 2014 / Accepted: 16 February 2015/Published online: 7 March 2015

(C) The Author(s) 2015. This article is published with open access at Springerlink.com

\begin{abstract}
Infiltration of tool steels with copper is a suitable and cheap method to create dense parts using powder metallurgy. In this work, it is shown that the copper network that forms inside the steel skeleton during infiltration enhances the thermal conductivity of the resulting composite. The level of enhancement is dependent on the thermal conductivity of the copper phase and the volume fraction of copper. Multiple heat treatments of this composite revealed a strong dependency between the thermal conductivity of the composite and the solution state of $\mathrm{Fe}$ in the copper network. The latter is highly dependent on the heat-treated condition of the multi-phase material. Using infiltration, the thermal and electrical conductivity was increased from 21.3 to $50.1 \mathrm{Wm}^{-1} \mathrm{~K}^{-1}$ and from 2.5 to $7.7 \mu \Omega^{-1} \mathrm{~m}^{-1}$, respectively, for aged steel-copper composite in comparison with original X245VCrMo9-4-4 steel. In addition, a model alloy that represents the copperphase network in the composite was manufactured. By measuring both, the thermal conductivity of this model alloy and the bulk steel, and comparing it to the data for the composite, different models for calculating the overall conductivity of the composite are discussed.
\end{abstract}

\footnotetext{
S. Klein $(\bowtie) \cdot$ W. Theisen

Ruhr-University Bochum, Universitätsstraße 150,

44801 Bochum, Germany

e-mail: klein@wtech.rub.de

W. Theisen

e-mail: theisen@wtech.rub.de

S. Weber

Bergische Universität Wuppertal, Bahnhofstr. 15,

42651 Solingen, Germany

e-mail: weber.fuw@uni-wuppertal.de
}

\section{Introduction}

Tool steels are usually designed with respect to their mechanical properties, particularly wear resistance, hardness, strength, toughness and, to a lesser extent, corrosion resistance $[1,2]$. In the last decades, much effort has been spent onto increasing these properties by optimizing alloying composition, heat treatment, and the production route. During the last few years, development and research has focused on additional properties, especially the thermal conductivity [3-5], which has resulted in newly developed steels optimized for high thermal conductivity [6-8]. Previous work showed that thermal conductivity is not only influenced by chemical composition, but also strongly by heat treatment $[9,10]$. This influence is even greater on steels with a high volume fraction of precipitates, such as carbide-rich cold-work tool steels [11].

In many advanced industrial applications, the commonly used cast and forged tool steels are being increasingly substituted by steels produced by powder metallurgy (PM). These steels can be manufactured from a mixture of binary or ternary powders or, for the most homogenous microstructure, from a single fully prealloyed, atomized steel powder. Compaction of these powders can be carried out either by solid-state sintering, liquid-phase sintering (LPS), super-solidus liquid-phase sintering (SLPS), or hot isostatic pressing (HIP). Except for solid-state sintering, all these techniques are able to create a fully densified material; however, they are often associated with high costs and different kinds of microstructure [12].

Another method to achieve a fully densified PM tool steel is to fill the pores of a solid-state sintered part with a lower melting metal, commonly copper. This technique is called infiltration and is widely used, e.g., in the automotive industry to produce valve seat rings and leads. 
Infiltration closes the open pores of sintered parts, to create a copper network in the material, which improves the mechanical properties by eliminating notches [13, 14].

Parts produced by infiltration contain a certain amount of copper, commonly 10 to $15 \mathrm{vol} \%$, depending on the open porosity after sintering [13]. Copper is used because of its good behavior during infiltration: It does not form any intermetallic phases with $\mathrm{Fe}$, has limited solubility for $\mathrm{Fe}$, and a good wettability on Fe. Copper itself is generally used as a technical material because of its superior physical properties. In its pure state, it has an exceptionally high thermal and electrical conductivity, up to $394 \mathrm{Wm}^{-1} \mathrm{~K}^{-1}$ and $58 \mu \Omega^{-1} \mathrm{~m}^{-1}$, respectively [15], compared to about 10 to $20 \mathrm{Wm}^{-1} \mathrm{~K}^{-1}$ and 1.1 to $2.0 \mu \Omega^{-1} \mathrm{~m}^{-1}$ for most tool steels [16]. Therefore, it is one of the most popular materials for many technical applications, such as heat exchangers as well as electrical and thermal conductors, etc.

Because of its high conductivity, it seems possible that the copper network residing in infiltrated parts increases their thermal (and electrical) conductivity. If this is the case, infiltration provides an opportunity to produce parts whose mechanical properties are dominated by the sintered steel, whereas the copper network increases their thermal and electrical conductivity. Provided, the interaction between the tool-steel skeleton and the copper network as well as the influence of the copper network and its geometry are known, parts could be manufactured, whose mechanical and physical properties could be tailored by selecting an appropriate steel and volume fraction of the copper.

The present work investigates the ability to create a copper-infiltrated cold-work tool steel with high thermal conductivity as well as the influence of heat treatment on its thermal conductivity. Additionally, a model alloy with the same chemical composition as the copper network residing in the infiltrated steel is investigated. Together with hot isostatically pressed bulk material of the steel X245, this allows the measurement and discussion of the properties of the single phases compared to the composite. Future studies will focus on the mechanical properties and the temperature dependency of the physical properties.

\section{Experimental}

Three materials were used in this investigation: firstly, the composite material named X245-Cu, which consists of solidstate sintered PM cold-work tool steel DIN EN ISO 4957 X245VCrMo9-4-4 (chemical composition is given in Table 1), that has been infiltrated with electrolytic copper; secondly, the same steel created by HIP (referred to as X245HIP); thirdly, the model alloy $\mathrm{CuFe} 3$, which recreates the copper network in the infiltrated steel by alloying electrolytic copper with 3 mass\% Fe.
Table 1 Chemical composition of the investigated X245 alloy in mass $\%$

\begin{tabular}{llllllllll}
\hline $\mathrm{C}$ & $\mathrm{Si}$ & $\mathrm{Mn}$ & $\mathrm{Cr}$ & $\mathrm{Mo}$ & $\mathrm{V}$ & $\mathrm{W}$ & $\mathrm{Co}$ & $\mathrm{Ni}$ & $\mathrm{Fe}$ \\
\hline 2.47 & 0.48 & 0.43 & 4.03 & 3.79 & 9.13 & 1.04 & 1.28 & 0.20 & bal. \\
\hline
\end{tabular}

Materials, processing, and heat treatment

The composite material $\mathrm{X} 245-\mathrm{Cu}$ is manufactured in a twostep process that comprises solid-state sintering of the steel skeleton and subsequent infiltration with liquid copper. To retain a high open porosity, only the particle fraction from 63 to $80 \mu \mathrm{m}$ is used for sintering. The steel X245 is provided as gas atomized, prealloyed steel powder by Böhler Edelstahl $\mathrm{GmbH}$. In its initial state, it consists of a major fraction of $\mathrm{V}_{8} \mathrm{C}_{7}$ carbides and a minor fraction of $\mathrm{Mo}_{2} \mathrm{C}$ carbides, residing in a matrix with a huge amount of retained austenite and a small amount of martensite. The microstructural changes and sintering behavior of this steel has already been deeply analyzed by Blüm [17] and Krasokha [18]. The microstructure of the powder is shown in Fig. 1. In accordance with these studies, a sintering temperature of $1200{ }^{\circ} \mathrm{C}$ was chosen. This temperature is slightly lower than $T_{\text {sol }}\left(1237{ }^{\circ} \mathrm{C}\right)$ which thus prevents the formation of a liquid phase. Sintering was performed in a vacuum radiation furnace ( $p=5 \times 10^{-3}$ mbar) by heating the powder at $1200{ }^{\circ} \mathrm{C}$ for $1 \mathrm{~h}$ in an alumina crucible. The sintered skeleton had a diameter of about $45 \mathrm{~mm}$ and a height of about $60 \mathrm{~mm}$.

Subsequently, the material was allowed to cool passively. Infiltration was performed by placing granulated electrolytic copper on the sintered steel skeleton, and then heating both above the solidus temperature of the copper,

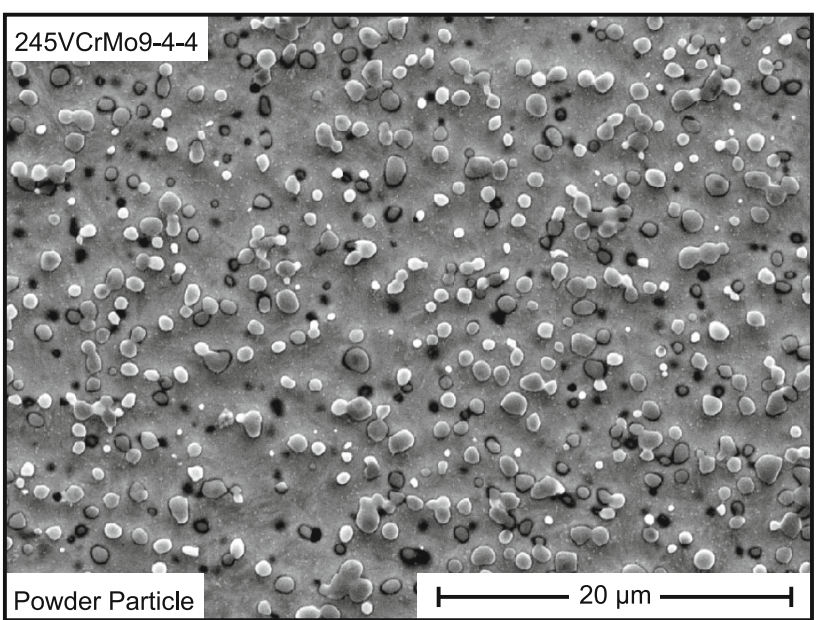

Fig. 1 Microstructure of a X245VCrMo9-4-4 powder particle, SE contrast. The steel consists of $\mathrm{V}_{8} \mathrm{C}_{7}$-carbides (big, gray, globular precipitates) and some $\mathrm{Mo}_{2} \mathrm{C}$-carbides (small, black dots), residing in a martensitic matrix with little retained austenite (after hardening) 
in this case to $1120{ }^{\circ} \mathrm{C}$, with a preheating step of $60 \mathrm{~min}$ at $1000{ }^{\circ} \mathrm{C}$. After maintaining this temperature for $1 \mathrm{~h}$, the composite was cooled passively below the solidification temperature and then gas-cooled to ambient temperature. Temperature profiles for sintering and infiltration are shown in Fig. 2. The microstructure of the resulting composite material is shown in Figs. 3 and 4.

For the sintered and infiltrated composite, the remaining closed porosity was determined by quantitative image analysis, revealing a porosity of less than $0.2 \mathrm{vol} \%$. All detected pores were identified as residual inner pores of the steel powder, originating from atomization. Using the measured densities of the composite, the steel X245-HIP (corrected by the value of inner porosity) and the model alloy $\mathrm{CuFe} 3$, the volume fraction of the copper network was determined as $35 \mathrm{vol} \%$, which was also confirmed by quantitative image analysis.

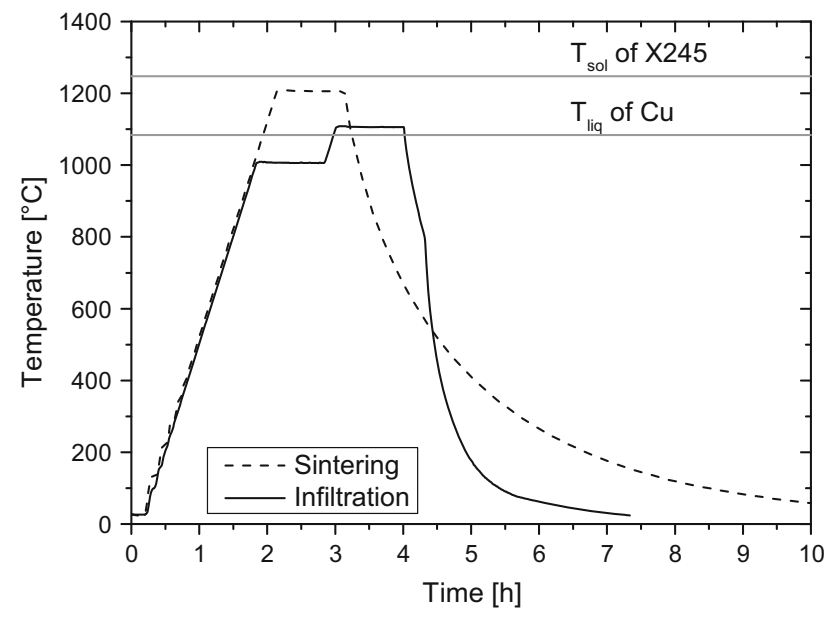

Fig. 2 Temperature versus time plot of the sintering and infiltration processes

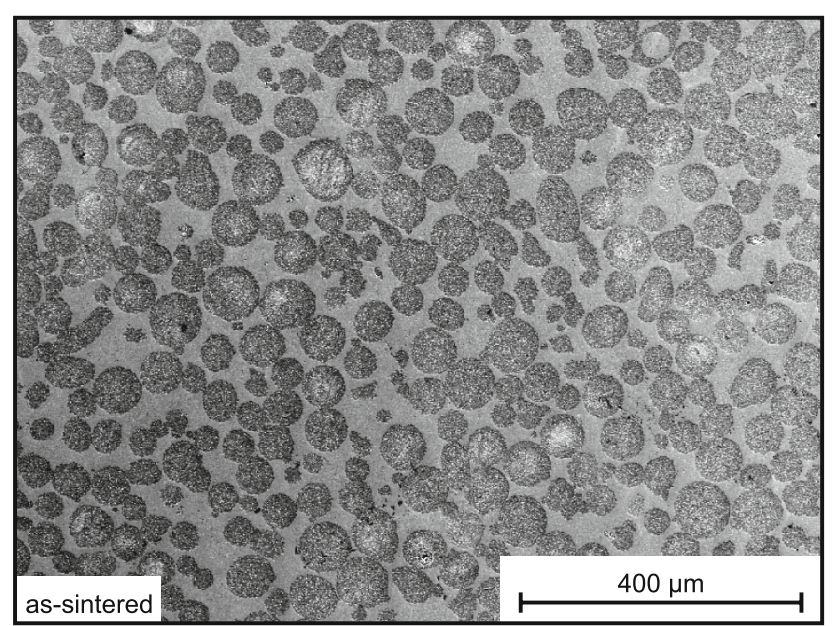

Fig. 3 Steel skeleton infiltrated with electrolytic copper. SEM image with SE contrast, $20 \mathrm{kV}$

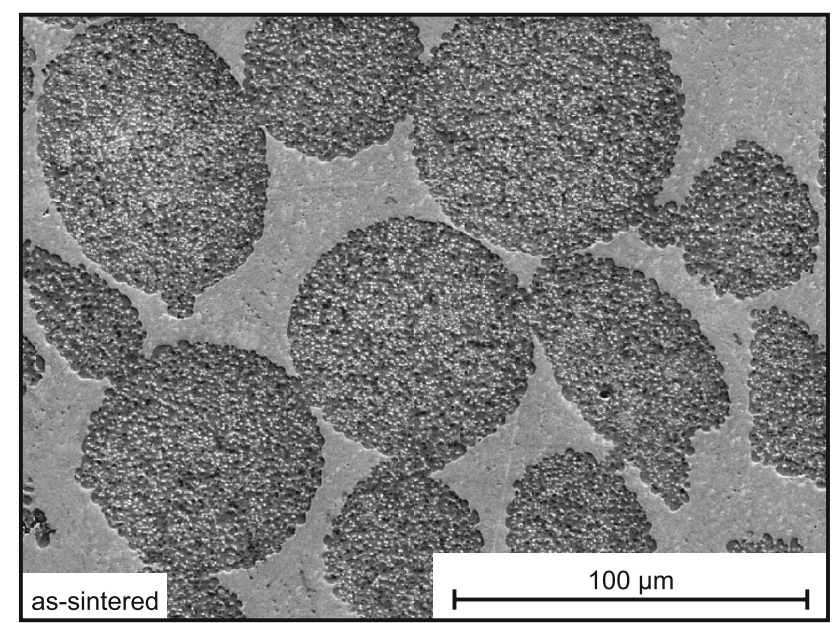

Fig. 4 More detailed SEM image of the infiltrated steel skeleton with SE contrast

The hot isostatically pressed steel X245-HIP is an industrial-grade material provided by Böhler Edelstahl GmbH that therefore needed no additional production steps.

The $\mathrm{CuFe} 3$ model alloy was produced by mixing granular electrolytic copper with pure iron powder and melting the mixture in a vacuum induction furnace in a graphite crucible. The bulk cast slug was then hot-rolled, cold-rolled, and recrystallized at $400{ }^{\circ} \mathrm{C}$ for $15 \mathrm{~min}$.

All materials were solution annealed using radiation furnaces at $1050{ }^{\circ} \mathrm{C}$ for $30 \mathrm{~min}$ in inert gas, followed by water quenching, and optional aging using three sequent aging steps at $550{ }^{\circ} \mathrm{C}$ for $8 \mathrm{~h}$ per step. For aging, convectional furnaces with ambient atmosphere were used.

For the measurements, specimens with the following dimensions were cut: $10 \times 10 \times 1.5 \mathrm{~mm}$ for laser-flash, $4 \times 4 \times 1.5 \mathrm{~mm}$ for $\mathrm{mDSC}$, and $4 \times 4 \times 20 \mathrm{~mm}$ for electric resistivity.

\section{Equilibrium calculations}

The thermodynamic equilibria were calculated using the Calphad software Thermo-Calc ${ }^{\circledR}[19]$. Based on the chemical composition given in Table 1, the phase diagram of X245VCrMo9-4-4, shown in Fig. 5, was calculated with the TCFe7 database [20]. From this data, the temperatures for austenitizing, solution annealing, sintering, and aging were chosen. Thermo-Calc ${ }^{\circledR}$ and the TCBin database [21] were used to calculate the solubility of $\mathrm{Fe}$ in $\mathrm{Cu}$ and $\mathrm{Cu}$ in $\mathrm{Fe}$ at the infiltration temperature $\left(1120^{\circ} \mathrm{C}\right)$, solution annealing temperature $\left(1050{ }^{\circ} \mathrm{C}\right)$, and aging temperature $\left(550^{\circ} \mathrm{C}\right)$.

By adding 39.8 mass\% (35.0 vol\%) $\mathrm{Cu}$ to the composition, proportionally aligning the mass fraction of the other elements, equilibrium calculations for the composite 


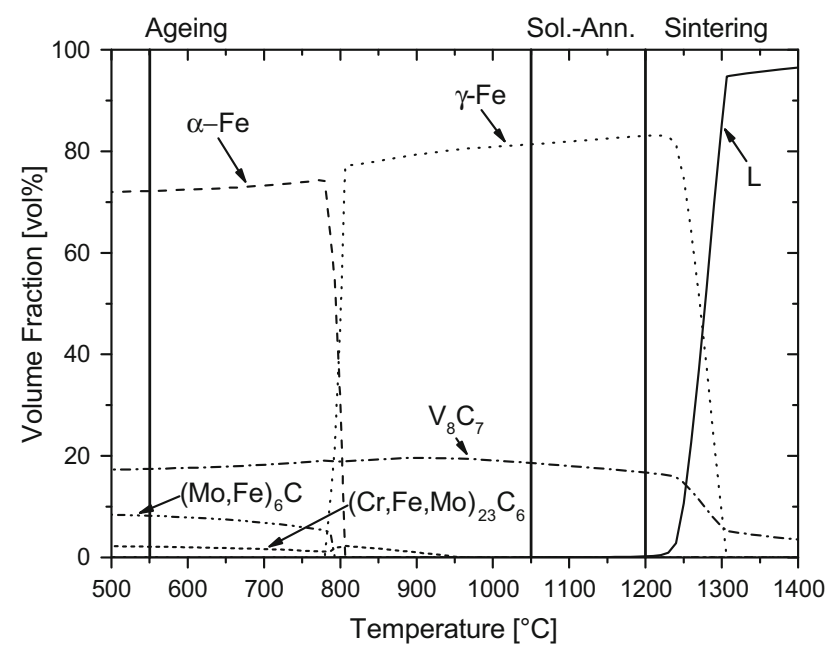

Fig. 5 Calculated phase contents of X245VCrMo9-4-4. Calculations were performed with Thermo-Calc ${ }^{\circledR}$ and TCFe7 database

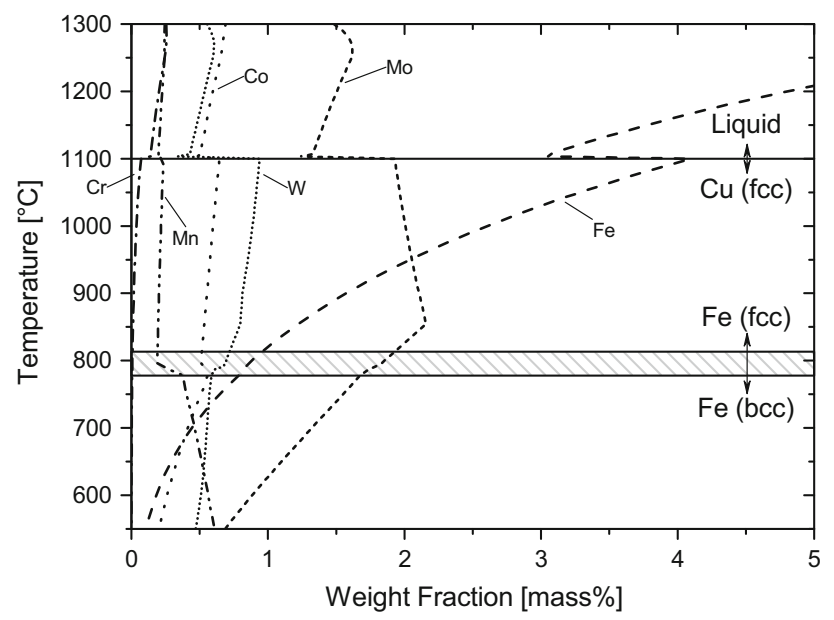

Fig. 6 Calculated equilibrium composition of the copper phase in $\mathrm{X} 245-\mathrm{Cu}$. Elements with a maximum fraction below 0.2 mass\% are not shown

material $\mathrm{X} 245-\mathrm{Cu}$ were performed. This technique was used to calculate the temperature-dependent equilibrium composition of the copper phase for all alloying elements of X245VCrMo9-4-4. The results are given in Fig. 6.

Measurement of the physical properties

In this work, the thermal conductivity was determined using the dynamic method described by Tritt [22]. Accordingly, the thermal diffusivity $a$, heat capacity $\mathrm{c}_{\mathrm{p}}$, and density $\rho$ were measured separately to allow calculation of the thermal conductivity $\lambda$ using the relation:

$\lambda=a \cdot \rho \cdot c_{\mathrm{p}}$

All measurements were repeated at least three times with three different specimens. The resulting mean values and standard deviations were plotted. A laser-flash device type LFA-1000 from Linseis Messgeräte $\mathrm{GmbH}$ was used for measuring the thermal diffusivity. Its accuracy is about $\pm 3 \%$. Values were measured at $20^{\circ} \mathrm{C}$ and calculated according to Eq. 2 where $L_{0}$ is the thickness of the specimen and $t_{0.5}$ is the time to reach half of the temperature increase induced by the laser pulse.

$a=1.38 \cdot \frac{L_{0}^{2}}{\pi^{2} \cdot t_{0.5}}$

The density was measured on the basis of the Archimedes buoyancy principle by measuring the weight in air and in water on a balance having a precision of $0.01 \mathrm{mg}$ (the weight of the specimen was about $1.5 \mathrm{~g}$ ).

The specific isobaric heat capacity was measured using modulated differential scanning calorimetry (mDSC). Measurements were carried out in $\mathrm{Pt} / \mathrm{Rh}$ pans with lids in a dynamic He atmosphere using a DSC 2920 CE from TA Instruments $\mathrm{GmbH}$, exhibiting a accuracy of $\pm 1 \%$ for the used specimen. Before every sequence, a baseline calibration and a signal calibration with a sapphire standard were performed.

The electric conductivity was derived from the specific resistivity, which was measured using the four-wire method. Experiments were taken out with a LSR 1100 from Linseis Messgeräte GmbH with an accuracy of $\pm 0.2 \%$.

\section{Results and discussion}

Characterization of the resulting composite

The Figs. 3 and 4 show cross sections of the composite $\mathrm{X} 245-\mathrm{Cu}$. This material, created by infiltration with liquid electrolytic copper, consists of a carbide-rich, sintered steel skeleton containing an interconnected copper network residing in its formerly open porosity. The particles forming the steel skeleton were only sintered slightly, resulting in a poor connection of the particles. EDS measurements of the copper network reveal a $\mathrm{Fe}$ content of 3 mass\% .

Equilibrium calculations

Since the diffusivity in the liquid copper is about 6 to 7 magnitudes higher than in the solid state, the transport of alloying elements from the steel component into the infiltrating copper is much faster in the liquid state than in the solid state [23-25].

As a result of fast cooling after infiltration, most of the transport of atoms into the copper takes place during the infiltration step. Assuming that the state of the liquid copper phase equals the equilibrium state after a short time, 
equilibrium calculations with the Calphad method can be used to approximate the chemical composition of the copper phase at the infiltration temperature. Due cooling, the previously dissolved alloying elements remain in the copper network, either dissolved in the copper matrix or as precipitates.

The investigated system is rather complex and contains many phases with different base elements: Fe in the steel matrix and $\mathrm{Cu}$ in the copper network as well as different carbides residing in the steel. No available thermodynamic database represents both cases: a complex steel with multiple phases and copper-based alloys. Nevertheless, the $\mathrm{TCFe} 7$ database contains extensive information in addition to Fe-based systems. To at least check the correctness of the data for high $\mathrm{Fe}$ contents in the $\mathrm{Cu}-\mathrm{Fe}$ system, the corresponding phase diagram was calculated and compared to data calculated using the binary TCBin database and experimental data from Boltax et al. [26] (see Fig. 7). Although both show good agreement in the solid state, the experimental data for the liquid phase differs, whereas the data calculated with the binary database is identical. Measuring the chemical composition of the copper phase after infiltration using EDS shows good agreement between the Fe content and the calculated value (Table 2). Only Fe and $\mathrm{Si}$ could be identified as components of the $\mathrm{Cu}$ phase by EDS and only the Fe signal was high enough to be quantified.

Figure 6 shows the calculated chemical composition of the copper phase in dependence of temperature. At lower temperatures, the content of the relevant elements $\mathrm{Fe}, \mathrm{Cr}$, $\mathrm{W}$, and Mo decreases. Since their mobility is also lowered, precipitation of these elements inside the copper matrix is

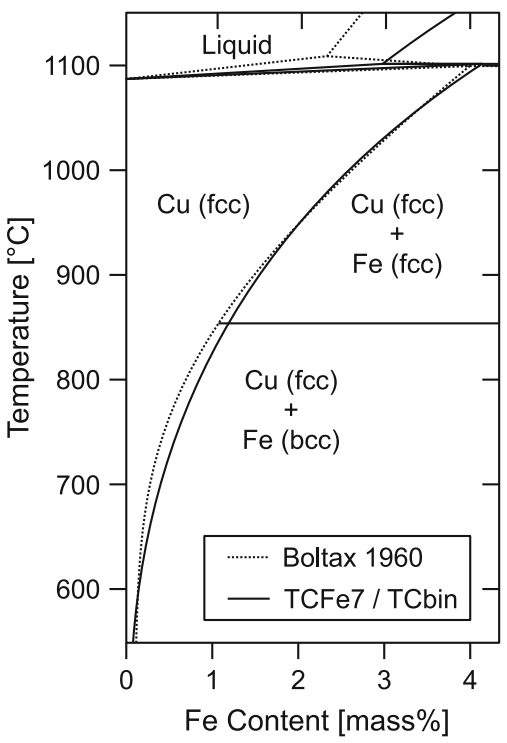

Fig. 7 Calculated phase diagram of the $\mathrm{Cu}-\mathrm{Fe}$ system on the $\mathrm{Cu}$-rich side. Data from [26] is shown for comparison to be expected. On the basis of these prerequisites, equilibrium calculations can be performed with the previously calculated chemical composition of the liquid copper phase at the infiltration temperature of $1120{ }^{\circ} \mathrm{C}$. The results of this calculation are shown in Fig. 8, which reveals that $\alpha$ and $\gamma$-Fe are the only stable phases besides fcc copper, with $\alpha-\mathrm{Fe}$ being stable at the aging temperature $\left(550{ }^{\circ} \mathrm{C}\right)$.

Effect of heat treatment on the thermal conductivity

A comparison of the thermal conductivity of the differently heat-treated X245-Cu (Fig. 9) composite specimens reveals a huge impact of aging on the thermal and electrical conductivities. This difference is mostly caused by changes in the thermal diffusivity (Fig. 10) because the specific heat capacity and density of $\mathrm{X} 245-\mathrm{Cu}$ are largely unaffected by the heat treatment (Fig. 11). Furthermore, most of the change is related to changes in the copper phase because the thermal conductivity of bulk X245VCrMo9-4-4 in the quenched or aged state differs only between $14.7 \pm$ $2.8 \mathrm{Wm}^{-1} \mathrm{~K}^{-1}$ and $21.3 \pm 2.6 \mathrm{Wm}^{-1} \mathrm{~K}^{-1}$, respectively.

This behavior can be explained well with the findings of the thermodynamic calculations ("Equilibrium calculations" section). Due to the decreasing solubility of $\mathrm{Fe}$ in the $\mathrm{Cu}$ during solidification (see Fig. 7), precipitation of $\mathrm{Fe}$ occurs after infiltration, thus raising the purity of the $\mathrm{Cu}$ matrix and with it the conductivity of the $\mathrm{Cu}$ network. During solution annealing at $1050{ }^{\circ} \mathrm{C}$ for $30 \mathrm{~min}$, all $\mathrm{Fe}$ precipitates dissolve in the $\mathrm{Cu}$ matrix, leading to a re-solvation of $\mathrm{Fe}$, which thus lowers the conductivity. On the other hand, when aged at $550{ }^{\circ} \mathrm{C}, \mathrm{Fe}$ precipitates again and the conductivity increases.

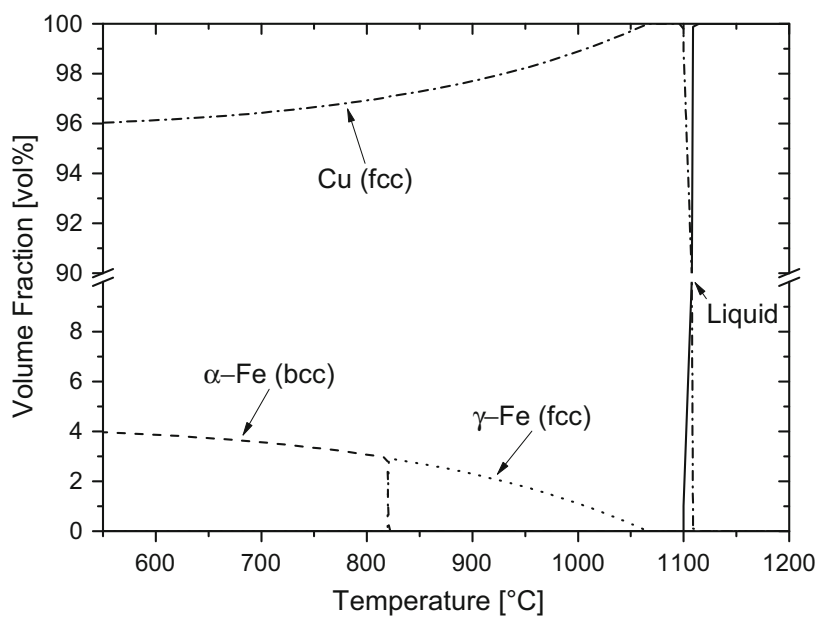

Fig. 8 Stable phases in the copper network of X245-Cu after infiltration. The calculation is based on the calculated composition of the liquid copper at $1120^{\circ} \mathrm{C}$ (see Table 2) 


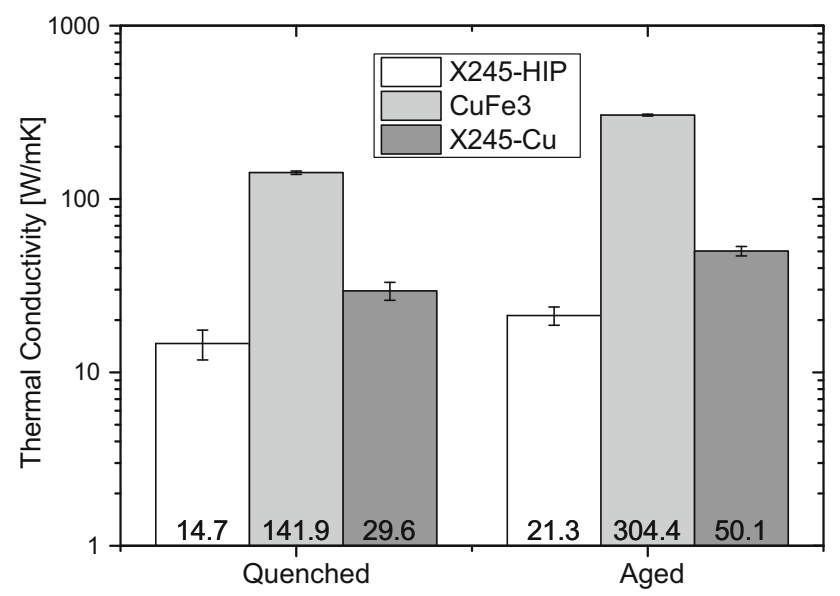

Fig. 9 Thermal conductivity of the investigated X245 steel, X245-Cu composite, and $\mathrm{CuFe} 3$ alloy in the quenched state and in the quenched and aged state

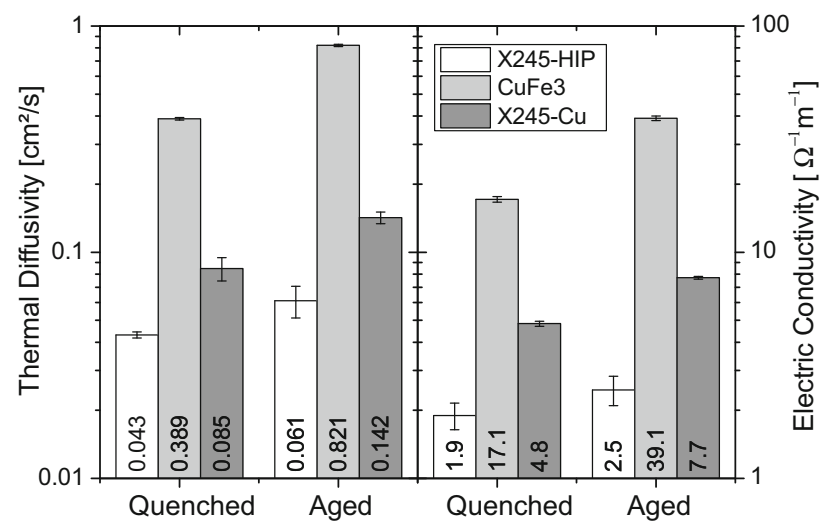

Fig. 10 Thermal diffusivity and electrical conductivity of the investigated X245 steel, X245-Cu composite, and $\mathrm{CuFe} 3$ alloy in the quenched state and in the quenched and aged state

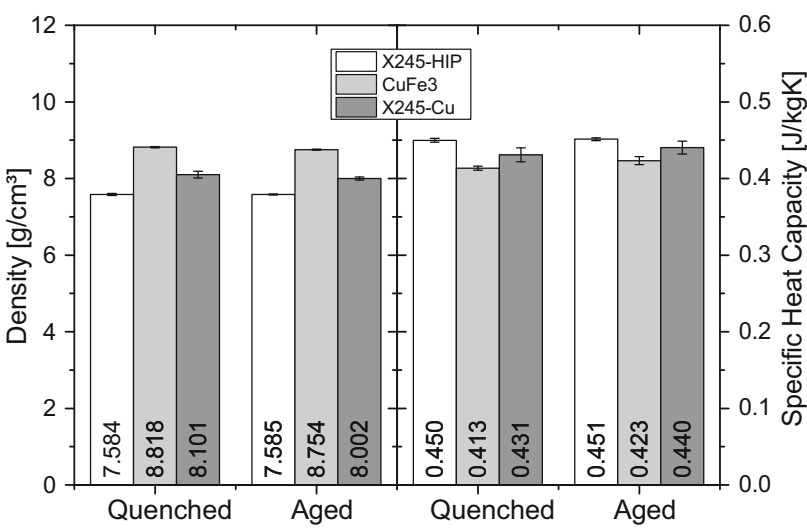

Fig. 11 Density and specific isobaric heat capacity of the investigated X245 steel, X245-Cu composite, and CuFe3 alloy in the quenched state and in the quenched and aged state
The precipitation behavior was confirmed using SEM imaging (Figs. 12, 13, 14). The precipitates occurring after infiltration have a dendritic shape (Fig. 12), which indicates that they formed within the liquid copper. After quenching in water, no precipitates were found in the $\mathrm{Cu}$ network (Fig. 13). However, when aged at $550{ }^{\circ} \mathrm{C}$, new globular shaped $\mathrm{Fe}$ precipitates formed in the copper (Fig. 14). These precipitates were identified as being $\mathrm{Fe}$ based by EDS, their shape is no further dendritic but globular due to solid-state precipitation. Figure 15 shows a schematic of the described processes.

The fact that the precipitation of Fe enhances the conductivity of the copper agrees well with the results of [26],

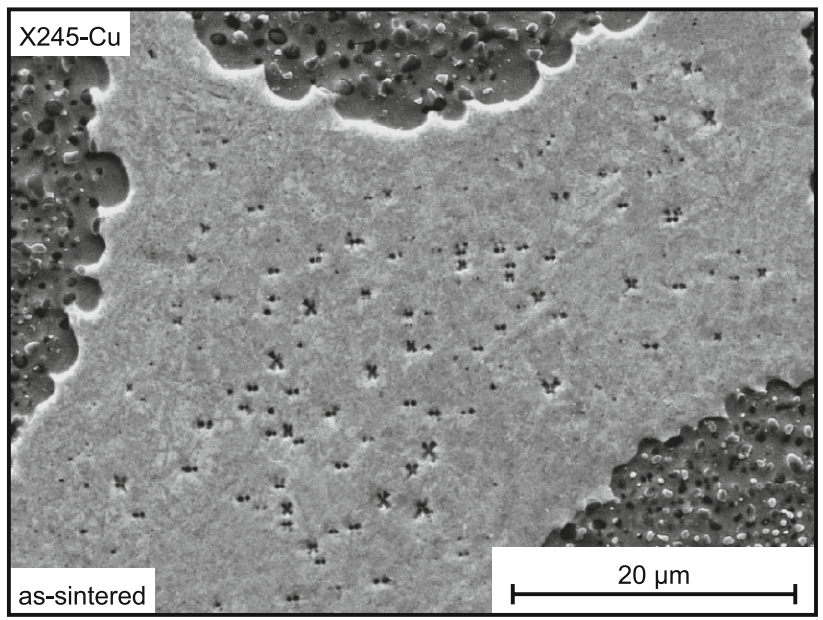

Fig. 12 SEM image with SE contrast of the X245-Cu composite. The iron precipitates in the copper matrix (lighter field) show a dendritic shape and a diameter of up to $2 \mu \mathrm{m}$ after infiltration and furnace cooling

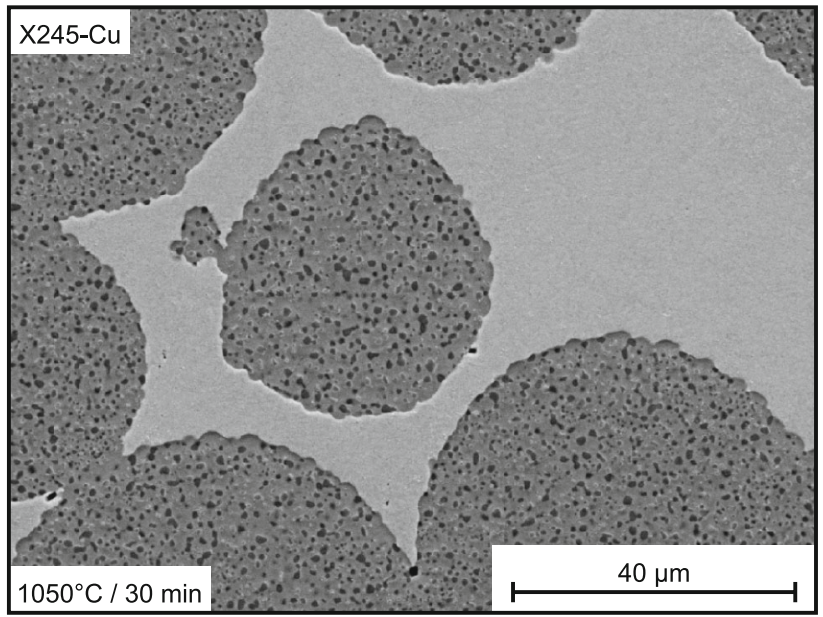

Fig. 13 SEM image with SE contrast of the X245-Cu composite. No precipitates are visible in the matrix of the infiltrated copper (lighter field) after solution annealing at $1050{ }^{\circ} \mathrm{C}$ for $30 \mathrm{~min}$ 


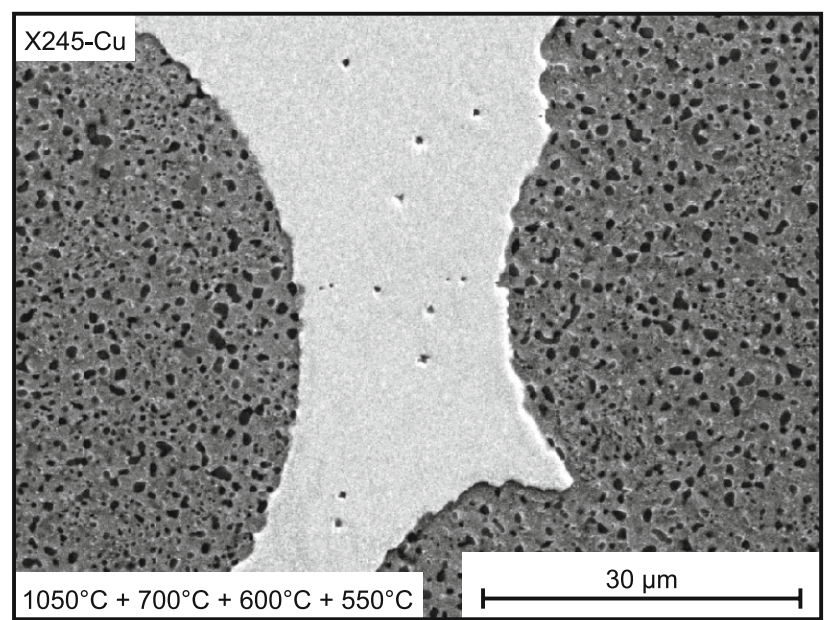

Fig. 14 SEM image with SE contrast of the X245-Cu composite. Globular Fe precipitates reside in the matrix of the infiltrated copper (lighter field) after solution annealing at $1050{ }^{\circ} \mathrm{C}$ for $30 \mathrm{~min}$, quenching and aging at $550{ }^{\circ} \mathrm{C}$ for $3 \times 8 \mathrm{~h}$

who found that precipitates had a much lower impact on the electric conductivity of copper than that induced by substitutional solvation of $\mathrm{Fe}$ in the matrix. Most of the change in conductivity of the copper phase is induced by the solution state of Fe. This is because $\mathrm{Fe}$ has one of the highest impacts on the conductivity of $\mathrm{Cu}$ when solvated, as has been shown by Linde [27] and Kierspe [28]. By removing $\mathrm{Fe}$ from the $\mathrm{Cu}$ matrix through precipitation, the purity of the matrix rises. Of course, the Fe precipitates reduce the overall thermal conductivity owing to the additional interfaces between the $\mathrm{Cu}$ matrix and the $\mathrm{Fe}$ precipitates, and to the lower conductivity of the Fe precipitates themselves. Below a critical size of about $1 \mu \mathrm{m}$, they behave similarly to lattice defects, because the interfacial thermal barrier resistance is high compared to the contribution of the precipitate to conductivity [29, 30]. Thus, the influence of precipitated $\mathrm{Fe}$ is much lower than in the dissolved state, as it was already hypothesized by [26]

Contribution of the components to the thermal conductivity of $\mathrm{X} 245-\mathrm{Cu}$

Since the copper network controls the conductivity of the $\mathrm{X} 245-\mathrm{Cu}$ composite, it is interesting to measure the influence of heat treatment on its thermal conductivity directly. This was achieved by manufacturing the $\mathrm{CuFe} 3$ model alloy with a chemical composition equal to that of the copper network after infiltration, which was measured by EDS (Table 2).

The physical properties of this model alloy were measured in the solution-annealed and aged state. Solution annealing was performed at $1050{ }^{\circ} \mathrm{C}$ for $30 \mathrm{~min}$, followed by quenching in water and aging at $550{ }^{\circ} \mathrm{C}$ for $24 \mathrm{~h}$. Measurements show a high impact of the heat treatment on the thermal and electrical conductivities of $\mathrm{CuFe} 3$, similar to those of the composite. At room temperature, the solution-annealed $\mathrm{CuFe} 3$ shows a thermal conductivity of $141.9 \pm 3.1 \mathrm{Wm}^{-1} \mathrm{~K}^{-1}$, which increases to $304.4 \pm$ $3.7 \mathrm{Wm}^{-1} \mathrm{~K}^{-1}$ after aging. This increase reflects the change in thermal conductivity of the X245-Cu composite,
Fig. 15 Diagram of the processes during heat treatment of X245-Cu composite. Gray regions-steel particles, white regions - copper matrix. a Diffusion of $\mathrm{Fe}$ into the copper network during infiltration. b Primary precipitation of $\mathrm{Fe}$ in the $\mathrm{Cu}$ melt during solidification c Dissolution of Fe precipitates in the copper network when solution annealed and quenched. d Solid-state precipitation of $\mathrm{Fe}$ in the copper network due to aging

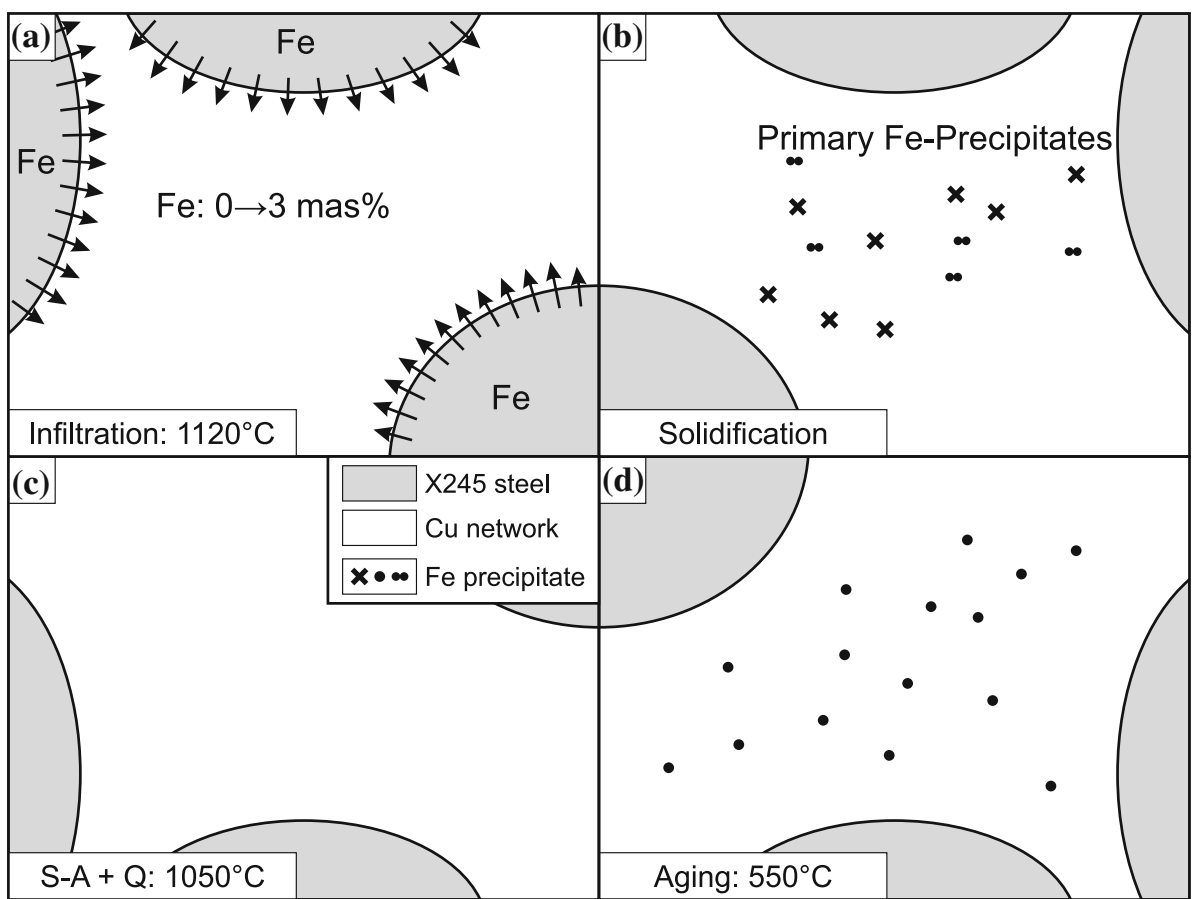


Table 2 Chemical composition of the phases in X245-Cu composite in mass \% : (a) copper infiltrated at $1120{ }^{\circ} \mathrm{C}$; calculated with Thermo$\mathrm{Calc}^{\circledR}$ and TCFe7 at $1120{ }^{\circ} \mathrm{C}$, (b) copper infiltrated at $1120{ }^{\circ} \mathrm{C}$; measured with EDS at $15 \mathrm{kV}$ at $20{ }^{\circ} \mathrm{C}$, (c) $\gamma$-Fe phase without the contact with copper at $1120^{\circ} \mathrm{C}$; calculated with Thermo-Calc ${ }^{\circledR}$ and $\mathrm{TCFe} 7$ (trace elements are not shown)

\begin{tabular}{lllllll}
\hline & $\mathrm{Fe}$ & $\mathrm{Mo}$ & $\mathrm{Co}$ & $\mathrm{W}$ & $\mathrm{Cr}$ & $\mathrm{Cu}$ \\
\hline (a) $\mathrm{Cu}$ liquid phase, Calphad & 3.23 & 1.35 & 0.52 & 0.44 & 0.15 & bal. \\
(b) $\mathrm{Cu}$ network, EDS & 3.02 & - & - & - & - & bal. \\
(c) $\gamma$-Fe, Calphad & bal. & 2.18 & 1.50 & 0.52 & 3.89 & - \\
\hline
\end{tabular}

which ranges between $29.6 \pm 3.6 \mathrm{Wm}^{-1} \mathrm{~K}^{-1}$ after solution annealing and $50.1 \pm 3.1 \mathrm{Wm}^{-1} \mathrm{~K}^{-1}$ after aging.

When comparing these values, one could expect an even higher thermal conductivity of the composite because it consists of $35 \mathrm{vol} \%$ copper. Assuming that the infiltrated copper has the same conductivity as the $\mathrm{CuFe} 3$ model alloy, the trivial rule of mixture by volume fraction, as described by Eq. 3 (where $\lambda_{x}$ is the thermal conductivity and $v_{x}$ is the volume fraction of the component), results in a thermal conductivity of $59.2 \mathrm{Wm}^{-1} \mathrm{~K}^{-1}$ in the solutionannealed state and $120.4 \mathrm{Wm}^{-1} \mathrm{~K}^{-1}$ in the aged state.

$\lambda_{\text {eff }}^{\max }=\lambda_{1} \cdot v_{1}+\lambda_{2} \cdot v_{2}$

Of course, this rule is overly simplified and ignores the effect of interfaces and internal geometry. It is only valid for a composite comprising parallel aligned stripes of two phases, which are parallel to the direction of heat transfer, with no interaction between the two phases. It equals the higher Wiener boundary [31] and gives the absolute maximum thermal conductivity, the composite can have. The other extreme is the serial alignment of the phases, representing the lower Wiener boundary (Eq. 4), giving the absolute minimum thermal conductivity the composite can have. See Table 3 for the results of all tested mixing models.

$\lambda_{\mathrm{eff}}^{\min }=\frac{\lambda_{1} \lambda_{2}}{\lambda_{1} \cdot v_{2}+\lambda_{2} \cdot v_{1}}$

While these boundaries are valid for every possible composite material, the range can be narrowed when assuming an isotropic material, like the investigated X245-Cu. This case is addressed by the bounds described by Hashin and Shtrikman [32], which are called the Hashin-Shtrikman boundaries (or HS-boundaries). They are calculated according to the Eqs. 5 and 6 for the lower and upper bound, respectively.

$$
\begin{aligned}
& \lambda_{\text {eff }}^{\min }=v_{1} \lambda_{1}+v_{2} \lambda_{2}-\frac{v_{1} v_{2}\left(\lambda_{1}-\lambda_{2}\right)^{2}}{3 \lambda_{2}-v_{2}\left(\lambda_{2}-\lambda_{1}\right)} \\
& \lambda_{\text {eff }}^{\max }=v_{1} \lambda_{1}+v_{2} \lambda_{2}-\frac{v_{1} v_{2}\left(\lambda_{1}-\lambda_{2}\right)^{2}}{3 \lambda_{1}-v_{1}\left(\lambda_{1}-\lambda_{2}\right)}
\end{aligned}
$$

The measured values for both states lay at the lower bound of this range, which predicts a thermal conductivity between 30.2 to $49.6 \mathrm{Wm}^{-1} \mathrm{~K}^{-1}$ in the quenched and 46.8 to $102.4 \mathrm{Wm}^{-1} \mathrm{~K}^{-1}$ in the aged state (see Table 3).

Other models do not predict a range but a single value of the overall thermal conductivity of the composite, which may be preferable if the model is close enough to the present case. The models from Maxwell [33], Lichtenecker [34], Bruggeman [35] and Hasselman and Johnson [36] were tested (see Table 3). However, their results are less accurate than the lower HS bound. The reasons will be discussed for each model.

$$
\lambda_{\mathrm{eff}}=\lambda_{1} \frac{\lambda_{2}+2 \lambda_{1}+2 v_{2}\left(\lambda_{2}-\lambda_{1}\right)}{\lambda_{2}+2 \lambda_{1}-v_{2}\left(\lambda_{2}-\lambda_{1}\right)}
$$

Table 3 Model calculations of thermal conductivity for steelcopper composite $\mathrm{X} 245-\mathrm{Cu}$ in

\begin{tabular}{|c|c|c|c|}
\hline & Dimension & $\mathrm{S}-\mathrm{A}$ and quenched & $\begin{array}{l}\text { S-A, quenched } \\
\text { and aged }\end{array}$ \\
\hline Volume fraction copper alloy & 1 & $v_{1}=0.35$ & $v_{1}=0.35$ \\
\hline Volume fraction steel & 1 & $v_{2}=0.65$ & $v_{2}=0.65$ \\
\hline Th. conductivity copper alloy & $\mathrm{Wm}^{-1} \mathrm{~K}^{-1}$ & $\lambda_{1}=141.9 \pm 3.1$ & $\lambda_{1}=304.4 \pm 3.7$ \\
\hline Th. conductivity steel & $\mathrm{Wm}^{-1} \mathrm{~K}^{-1}$ & $\lambda_{2}=14.7 \pm 2.9$ & $\lambda_{2}=21.3 \pm 2.5$ \\
\hline Model & $\begin{array}{l}\text { Additional } \\
\text { parameters }\end{array}$ & \multicolumn{2}{|c|}{$\begin{array}{l}\text { Calculated thermal } \\
\text { conductivity in }\left(\mathrm{Wm}^{-1} \mathrm{~K}^{-1}\right)\end{array}$} \\
\hline Wiener (Eqs. 4, 3) & & 21.4 to 59.2 & 31.6 to 120.4 \\
\hline Hashin-Shtrikman (Eqs. 5, 6) & & 30.2 to 49.6 & 46.8 to 102.4 \\
\hline Maxwell (Eq. 7) & & 49.6 & 98.0 \\
\hline Hasselman-Johnson (Eq. 8) & $\begin{array}{l}h_{c}=5 \times 10^{8} \mathrm{Wm}^{-1} \mathrm{~K}^{-1} \\
\quad \alpha=36 \mu \mathrm{m}\end{array}$ & 49.6 & 98.0 \\
\hline Lichtenecker (Eq. 9) & & 32.5 & 54.0 \\
\hline $\begin{array}{l}\text { Bruggeman-Landauer (Eq. } \\
\text { 11) }\end{array}$ & & 38.0 & 66.5 \\
\hline Measurement (Fig. 9) & & $29.6 \pm 3.6$ & $50.1 \pm 3.1$ \\
\hline
\end{tabular}
comparison with experimental data 
The model from Maxwell (Eq. 7) is only valid for a low fraction of dispersed particles, whose distance is greater than their size and which are randomly distributed. It is therefore not applicable for the investigated material and predicts a much too high thermal conductivity.

Hasselman and Johnson (Eq. 8) [36] assumed a very similar geometry like Maxwell. In addition, they consider the effects of interfaces and the mean free path by including the interfacial thermal conductance $h_{\mathrm{c}}$ between both phases and the sphere size $a$. In this case, $h_{\mathrm{c}}$ was estimated to $5 \times 10^{8} \mathrm{Wm}^{-2} \mathrm{~K}^{-1}$ according to [37].

$$
\lambda_{\text {eff }}=\lambda_{1} \frac{\left[2 \cdot v_{2}\left(\frac{\lambda_{2}}{\lambda_{1}}-\frac{\lambda_{2}}{a h_{\mathrm{c}}}-1\right)+\frac{\lambda_{2}}{\lambda_{1}}+\frac{2 \lambda_{2}}{a h_{\mathrm{c}}}+2\right]}{\left[v_{2}\left(1-\frac{\lambda_{2}}{\lambda_{1}}+\frac{\lambda_{2}}{a h_{\mathrm{c}}}\right)+\frac{\lambda_{2}}{\lambda_{1}}+\frac{2 \lambda_{2}}{a h_{\mathrm{c}}}+2\right]}
$$

Its result is identical to the Maxwell model, because the impact of both considered effects are low when a high contrast between the thermal conductivities of both phases is assumed. Furthermore, it is only defined for a low content of the dispersed phase.

A much simpler approach is the formula from Lichtenecker (Eq. 9). Originally, it is more an empirical formula without a well-founded physical model, but recent research showed a good agreement if both phases are randomly distributed [38].

$\lambda_{\text {eff }}=\lambda_{1}^{v_{1}} \cdot \lambda_{2}^{v_{2}}$

This formula gives the most accurate results beside the lower HS bound, but it gives no information for the reason of its good agreement. The model from Bruggeman-Landauer (Eq. 11) is sometimes considered an enhancement of Lichtenecker's model for anisotropic materials. Nevertheless, it is less accurate in the present case.

$k_{\mathrm{b}}=\lambda_{1}\left(3 v_{1}-1\right)+\lambda_{2}\left(3 v_{2}-1\right)$

$\lambda_{\mathrm{eff}}=\frac{k_{\mathrm{b}}+\sqrt{k_{\mathrm{b}}^{2}+8 \lambda_{1} \lambda_{2}}}{4}$

In summary, the formula of Lichtenecker and the model of the lower Hashin-Shtrikman bound are most accurate when calculating the overall thermal conductivity of the composite $\mathrm{X} 245-\mathrm{Cu}$.

This result is surprising, because the conceptional model of the upper bound is close to the present case; The upper bound is valid for a volume built from composite spheres with a low conducting core and a high conducting shell, resulting in isolated cores with a low thermal conductivity and a network of shells with a high conductivity [32]. The lower bound represents the opposite case, which is far from the investigated composite material X245-Cu.

The main difference between the upper HS-model and the material $\mathrm{X} 245-\mathrm{Cu}$ is the connection of the steel particles. Due to this, the particles are not isolated, instead they form a skeleton. This exception might be the reason for the significant difference between the upper HS bound and the measured thermal conductivity. Although the thermal conductivity of the bare steel skeleton is increased, the connections form an additional resistance in the otherwise high conducting phase of the copper network, thus reducing the overall thermal conductivity. It is unclear if this resistance is responsible for the discrepancy or if other effects apply, too.

One method to further investigate the applicability of the shown models is to simulate the heat flow using a representative FEM model. As pointed out by [39], this technique can be used to simulate the thermal conductivity of the composite and also take account of its inner geometry. In their study, the simulation gave more realistic results than the theoretical approaches, especially if the components had greatly differing thermal conductivities. A similar approach will be used to simulate the investigated $\mathrm{X} 245-\mathrm{Cu}$ composite. The results of this ongoing work will be topic of a future publication.

\section{Conclusions and summary}

The infiltration of tool steels with copper has the potential to produce composites with an interesting combination of physical and mechanical properties. The present study investigated the composite $\mathrm{X} 245-\mathrm{Cu}$, which consists of the sintered PM cold-work tool steel X245VCrMo9-4-4 that was infiltrated with 35 vol\% electrolytic copper. This composite material showed a thermal conductivity of $29.6 \pm 3.6 \mathrm{Wm}^{-1} \mathrm{~K}^{-1}$ in the solution-annealed state, which is high compared to most tool steels. Nevertheless, a even higher conductivity could be expected by the high copper content of the composite. The solvation of $\mathrm{Fe}$ from the steel into the liquid copper was found to provide the major contribution to the thermal resistance. It was then shown that the conductivity of the copper and with it, that of the composite was strongly influenced by heat treatment. This was possible due to the strong temperature dependency of the solubility of $\mathrm{Fe}$ in $\mathrm{Cu}$, which results in a rapid precipitation of $\mathrm{Fe}$ when aged at lower temperatures. The conductivity of the composite increased to $50.1 \pm$ $3.1 \mathrm{Wm}^{-1} \mathrm{~K}^{-1}$ by aging at $550{ }^{\circ} \mathrm{C}$ for $24 \mathrm{~h}$.

It is possible that even higher conductivities could be achieved by decreasing the amount of $\mathrm{Fe}$ that is solvated during infiltration. On the other hand, there is a need for a more reliable method of predicting the thermal conductivity of the composite using the parameters of the individual components. Indeed, a corresponding FEM model will be developed that will allow investigations of the effect of the composite's inner geometry on the thermal conductivity so that the geometry can be optimized with 
respect to a high conductivity. Further studies will focus on the mechanical properties of the composite.

Acknowledgements The authors gratefully acknowledge financial support from the Deutsche Forschungsgemeinschaft (DFG) under support code TH531/13-1. Further thanks go to Fabian Nowara and Robin Thiel, who were involved in gaining a part of the experimental results.

Open Access This article is distributed under the terms of the Creative Commons Attribution License which permits any use, distribution, and reproduction in any medium, provided the original author(s) and the source are credited.

\section{References}

1. Berns H, Theisen W (2008) Eisenwerkstoffe: Stahl und Gusseisen, 4th edn. Springer, Berlin

2. Dahl W (ed) (1993) Eigenschaften und Anwendungen von Stählen, vol 2, 1st edn. Verlag der Augustinus-Buchhandlung, Aachen

3. Valls I, Casas B, Rodriguez N (2009) Importance of tool material thermal conductivity in the die longevity and product quality in hpdc. In: Beiss P, Broeckmann C, Franke S, Keysselitz B (eds) Tool steels-deciding factor in worldwide production, vol 1 . Mainz, Aachen, pp 127-140

4. Valls I, Casas B, Rodriguez N, Paar U (2010) Benefits from using high thermal conductivity tool steels in the hot forming of steels. La Metallurgia Italiana - n. 11-12

5. Meurisse E, Ernst C, Bleck W (2012) Improvement of thermal conductivity of hot-work tool steels by alloy design and heat treatment. In: Leitner H, Kranz R, Tremmel A (eds) TOOL 2012: developing the world of tooling. Verlag Gutenberghaus, Knittelfeld, pp 215-224

6. Rovalma SA (2008) Warmarbeitsstahl. European Patent EP $1,887,096 \mathrm{~A} 1$

7. Rovalma SA (2008) Verfahren zur Einstellung der Wärmeleitfähigkeit eines Stahls, Werkzeugstahls, insbesondere Warmarbeitsstahl, und Stahlgegenstand. International Patent WO 2008/017341 A1

8. Gelder S, Jesner G (2012) New high performance hot work tool steel with improved physical properties. In: Leitner H, Kranz R, Tremmel A (eds) TOOL 2012: developing the world of tooling. Verlag Gutenberghaus, Knittelfeld, pp 199-206

9. Wilzer J (2012) On the relationship of heat treatment, microsctructure, mechanical properties, and thermal conductivity of tool steels. In: Leitner H, Kranz R, Tremmel A (eds) TOOL 2012: developing the world of tooling. Verlag Gutenberghaus, Knittelfeld, pp 143-152

10. Wilzer J, Lüdtke F, Weber S, Theisen W (2013) The influence of heat treatment and resulting microstructures on the thermophysical properties of martensitic steels. J Mater Sci 48(24):8483-8492. doi:10.1007/s10853-013-7665-2

11. Wilzer J, Weber S, Escher C, Theisen W (2014) Werkstofftechnische Anforderungen an Press-härtewerkzeuge am Beispiel der Werkzeugstähle X38CrMoV5-3, 30MoW33-7 und 60MoCrW288-4. HTM J Heat Treat Mater 69(6):325-332

12. Schatt W, Wieters K-P, Kieback B (2007) Pulvermetallurgie: Technologien und Werkstoffe, 2nd edn. VDI-Buch Springer, Berlin

13. Samal PK, Klar E (1998) Copper-infiltrated steels. In: ASM handbook. vol 7, pp 769-773

14. Bernier F, Beaulieu P, Baïlon J-P, L’Espérance G (2011) Effect of $\mathrm{Cu}$ infiltration on static and dynamic properties of PM steels. Powder Metall 54(3):314-319
15. Gottstein G (2007) Physikalische Grundlagen der Materialkunde. Springer, Berlin

16. Richter F (1983) Die wichtigsten physikalischen Eigenschaften von 52 Eisenwerkstoffen.Stahleisen Sonderberichte, Heft 10, Verlag Stahleisen

17. Blüm M (2014) Neuartige Schichtverbundwerkstoffe zur Standzeiterhöhung verschleißbeanspruchter Werkzeuge für die Mineralverarbeitung. Dissertation, Ruhr-Universität Bochum, Bochum

18. Krasokha N (2012) Einfluss der Sinteratmosphäre auf das Verdichtungsverhalten hochlegierter PM-stähle. Dissertation, Ruhr-Universität Bochum, Bochum

19. Andersson J-O, Helander T, Höglund L, Shi P, Sundman B (2002) Thermo-Calc \& DICTRA, computational tools for materials science. Calphad 26(2):273-312

20. Thermo-Calc Software AB (2013) TCFE7 steels/Fe-alloys database, version 7. Thermo-Calc Software AB, Stockholm

21. Thermo-Calc Software AB (2013) TCBin/Binary Solutions Database. Thermo-Calc Software AB, Stockholm

22. Tritt TM, Weston D (2010) Measurement techniques and considerations for determining thermal conductivity of bulk materials. In: Thermal conductivity, Physics of solids and liquids. Springer, New York, pp 187-203

23. Ohno R (1986) Rates of dissolution of solid iron, cobalt, nickel, and silicon in liquid copper and diffusion rate of iron from liquid cu-fe alloy into liquid copper. Metall Trans B 17(2):291-305

24. Butrymowicz DB, Manning JR, Read ME (1976) Diffusion in copper and copper alloys. Part IV. Diffusion in systems involving elements of group VIII. JPCRD 5(1):103-200

25. Butrymowicz DB, Manning JR, Read ME (1973) Diffusion in copper and copper alloys, Part I. Volume and surface self-diffusion in copper. JPCRD 2(3):643-655

26. Boltax A (1960) Precipitation processes in copper-rich copperiron alloys. Trans Am Inst Min Metall Eng 218(5):812-821

27. Linde JO (1931) Elektrische Eigenschaften verdünnter Mischkristallegierungen I. Goldlegierungen. Ann Phys 402(1):52-70

28. Kierspe W (1967) Über den Einfluß der Übergangselemente der ersten großen Periode auf die Leitfähigkeitseigenschaften von Kupfer. Universität zu Köln

29. Bhatt H, Donaldson KY, Hasselman DPH (1990) Role of the interfacial thermal barrier in the effective thermal diffusivity/conductivity of SiC-fiber-reinforced reaction-bonded silicon nitride. J Am Ceram Soc 73(2):312-316

30. Geiger AL, Hasselman DPH, Donaldson KY (1993) Effect of reinforcement particle size on the thermal conductivity of a particulate silicon carbide-reinforced aluminium-matrix composite. J Mater Sci Lett 12(6):420-423

31. Wiener O (1912) Die Theorie des Mischkörpers für das Feld der stationären Strömung. Abhandlungen der mathematisch-physischen Klasse der K. Sächs. Gesellschaft der Wissenschaften. Bd. 32. No. 6

32. Hashin Z, Shtrikman S (1961) Note on a variational approach to the theory of composite elastic materials. J Frankl Inst 271(4):336-341

33. Maxwell JC (1873) A treatise on electricity and magnetism. Clarendon press series. Clarendon Press, Oxford

34. Lichtenecker K (1926) Die Ableitung der logarithmischen Mischungsregel aus dem Maxwell-Rayleighschen Schrankenwertverfahren. Kolloidchemische Beihefte 23(1-9):285-291

35. Bruggeman DAG (1935) Berechnung verschiedener physikalischer konstanten von heterogenen substanzen. I. Dielektrizitätskonstanten und leitfähigkeiten der mischkörper aus isotropen substanzen. Ann Phys 416(7):636-664

36. Hasselman DPH, Johnson LF (1987) Effective thermal conductivity of composites with interfacial thermal barrier resistance. J Compos Mater 21(6):508-515 
37. Wang H, Xu Y, Shimono M, Tanaka Y, Yamazaki M (2007) Computation of interfacial thermal resistance by phonon diffuse mismatch model. Mater Trans 48(9):2349-2352

38. Simpkin R (2010) Derivation of Lichtenecker's logarithmic mixture formula from Maxwell's equations. IEEE Trans Microw Theory Tech 58(3):545-550
39. Zhang H, Zeng Y, Zhang H, Guo F (2010) Computational investigation of the effective thermal conductivity of interpenetrating network composites. J Compos Mater 44(10):12471260 